\title{
Prognostic value of tumor-infiltrating B lymphocytes and plasma cells in triple-negative breast cancer
}

\author{
Hajime Kuroda ${ }^{1,2}$ - Tsengelmaa Jamiyan ${ }^{2,3} \cdot$ Rin Yamaguchi $^{4} \cdot$ Akinari Kakumoto $^{1,5} \cdot$ Akihito Abe $^{1,6} \cdot$ Oi Harada $^{7}$. \\ Bayarmaa Enkhbat ${ }^{3}$. Atsuko Masunaga ${ }^{1}$
}

Received: 11 August 2020 / Accepted: 12 February 2021 / Published online: 25 February 2021

(c) The Author(s) 2021

\begin{abstract}
Background Recent investigations have demonstrated that the tumor microenvironment, including tumor-infiltrating lymphocytes (TILs), is an important factor in tumor growth and development. While the prognostic correlation of tumor-infiltrating T cells has been widely studied in breast cancer, that of tumor-infiltrating B cells and plasma cells has not received so much attention, especially in triple-negative breast cancer (TNBC).

Methods We investigated 114 patients with TNBC who had surgery between 2006 and 2019 at Dokkyo Medical University Hospital. Intratumoral (i) TILs were considered to be lymphocytes within cancer cell nests and directly infiltrating tumor cells. Similarly, stromal (s) TILs were considered to be lymphocytes within the tumor stroma, but not directly infiltrating tumor cells. CD20 +, CD38 + and CD138 + staining was determined by estimating the number of positive B cells.

Results sCD20 + TILs had prognostic significance for relapse-free survival (RFS) $(p=0.043)$ and overall survival (OS) $(p=0.027)$. The sCD $38+$ TILs were significantly related to favorable RFS $(p=0.042)$. iCD38, iCD138, and sCD138 was not significantly correlated with RFS ( $p=0.065, p=0.719, p=0.074)$ or OS $(p=0.071, p=0.689, p=0.082)$.

Conclusions The present study demonstrated that a high density of SCD20 + TILs was significantly related to favorable prognosis in both RFS and OS. Increased SCD38 + TILs in TNBC were correlated with a significantly favorable prognosis in RFS. These results indicate that TILs-B may have a profound influence on the clinical outcome of TNBC.
\end{abstract}

Keywords Breast $\cdot$ Triple negative cancer $\cdot$ Prognostic factor $\cdot$ CD20 $\cdot$ CD38 $\cdot$ CD138

Hajime Kuroda

kuroda.hajime@twmu.ac.jp

1 Department of Diagnostic Pathology, Medical Center East, Tokyo Women's Medical University, 2-1-10 Nishiogu, Arakawa-ku, Tokyo 116-8567, Japan

2 Department of Diagnostic Pathology, Dokkyo Medical University, Mibu, Japan

3 Department of Pathology and Forensic Medicine, Mongolian National University of Medical Sciences, Ulan Bator, Mongolia

4 Department of Pathology \& Laboratory Medicine, Kurume University Medical Center, Kurume, Japan

5 Department of Diagnostic Pathology, Nasu Red Cross Hospital, Otawara, Japan

6 Breast Center, Dokkyo Medical University, Mibu, Japan

7 Breast Center, Showa University, Tokyo, Japan

\section{Introduction}

Recent investigations have demonstrated that the tumor microenvironment, including tumor- infiltrating lymphocytes (TILs), is an important factor in tumor growth and development. While the prognostic correlation of tumorinfiltrating $\mathrm{T}$ cells has been widely studied in breast cancer, that of tumor-infiltrating B cells (TILs - B) and plasma cells has not received so much attention, especially in triple-negative breast cancer (TNBC). Several studies immunohistochemically investigated the prognostic influence of $\mathrm{CD} 20+, \mathrm{CD} 38+$, and CD138 + TILs on esophageal cancer, gastric cancer, colorectal cancer, melanoma, ovarian cancer, and non-small cell lung cancer [1-6]. Recently, several breast cancer researchers have reported that a predominance of TILs - B was correlated with favorable prognosis [7-13], while other studies discovered a negative association with prognosis $[14,15]$. The potential mechanisms of these results can be explained by B-cell characteristics; 
they may participate in the secretion of effector cytokines that can polarize $\mathrm{T}$ cells towards a Th1 or Th2 reaction, activate T-cell reactions through their role as antigen-presenting cells, while direct cytotoxicity in cancer has also been suggested [16]. Tertiary lymphoid structures (TLS) are constructed aggregates of lymphoid cells that resemble secondary lymphoid organs [17]. TLS present in human solid tumors are important to construct a favorable immune microenvironment to control tumor progression $[17,18]$. Their functions include B-cell activation, differentiation into plasma cells and antibody production [19] associated with anti-tumor responses [17, 19]. Invasive breast cancer has been categorized into several major subtypes based on gene expression profiles [20]. The term TNBC is defined by loss of the estrogen receptor (ER) and progesterone receptor $(\mathrm{PgR})$, and human epidermal growth factor receptor 2 (HER2) protein overexpression, which is known to have a negative prognosis.

The correlation between TILs-B such as CD20+, $\mathrm{CD} 38+$, and CD138 +, TLS, and breast cancer, especially in TNBC, is still being debated. We herein discuss the clinicopathological features and prognostic value of TILs-B analyzed with CD20 +, CD38 +, and CD138 + in TNBC.

\section{Materials and methods}

\section{Patients}

We investigated 114 patients with TNBC who had surgery between 2006 and 2019 at Dokkyo Medical University Hospital. Hematoxylin and eosin (H\&E) stained whole-tissue sections were estimated by two investigators (HK and TJ) without clinical information or prior histological results. Ethical approval for this study was obtained from the Dokkyo Medical University Ethics Committee.

\section{Immunohistochemistry (IHC)}

Using IHC, the specimens were stained with the following antibodies: ER (clone SP1, Novocastra (Leica), prediluted, nuclear), PgR (clone 1E2, Novocastra (Leica), prediluted, nuclear), HER2 (clone 4B5, Roche (VENTANA), prediluted, membranous), CD20 (CD20, clone L26, nichirei), CD38 (CD38, clone SPC32, Novocastra (Leica) 1:200), and CD138 (CD138, clone MI15, Novocastra (Leica)). Hematoxylin was used for counterstaining. The percentages of ER and PgR were estimated, as mentioned by the guideline, and a patient was determined to be "positive" if the breast tumor was confirmed to have at least $1 \%$ positive cells [21]. HER2-negative was considered to be staining with a score of $0 / 1+$. For score 2 staining, fluorescence in situ hybridization (FISH) was considered positive for HER2 amplification when the ratio of HER2 to chromosome enumeration probe 17 (CEP17) was $>2.0$ [22]. For mib-1 expression, the cutpoint value was set at $20 \%$ based on a previous report [23].

Assessment of the TILs on H\&E-stained full-face sections was conducted according to the International ImmunoOncology Biomarkers Working Group [24]. We evaluated two locations of TILs, the intratumoral (i) and stromal (s) parts, individually. iTILs were assessed as lymphocytes in direct cell-to-cell contact with tumor cells with no intervening stroma. sTILs were assessed as lymphocytes within the tumor stroma and not directly infiltrating tumor cells. The cut-point value was set at 30\% [25]. TLS were evaluated on whole H\&E sections and TLS-positive tumors were defined as having $\geq 1 \mathrm{TLS}$, and TLS-negative tumors were defined by the absence of TLS $(<1)$. The CD20+, CD38+, and CD138 + TILs were determined by calculating the number of positive cells [26]. For statistical analyses, the number of positive cells was categorized into low and high groups according to the cut-point value using the median (Figs. 1, 2).

\section{Statistical analysis}

The correlations between CD20+, CD38+, and CD138 + TILs and clinicopathological factors were assessed by the $x^{2}$-test. Relapse-free survival (RFS) was determined as the date of surgery to recurrence including loco-regional, or distant metastasis. Overall survival (OS) was defined as the time from the primary surgery to death by cancer or the time to the last follow-up for patients still alive. The RFS and OS curves were assessed using the Kaplan-Meier method, and the results were compared using the log-rank test. Univariate and multivariate Cox proportional hazard models were applied to identify clinicopathological factors that were correlated with survival rate, and hazard ratios (HRs) were noted as point evaluations with $95 \%$ confidence intervals (CI). IBM SPSS Statistics 26 (IBM, Armonk, NY, United States) was used for statistical analyses. Data were assumed to be statistically significant at $p<0.05$, and all $p$ values were two-tailed.

\section{Results}

The median age of breast cancer patients was 62 years (range 28-89) and 59 (51.8\%) were older than 60 years. The majority had an invasive ductal carcinoma (IDC) 88 (77.2\%), and a high histological grade $79(69.3 \%)$. There were 71 tumors of $\leq 2 \mathrm{~cm}(62.3 \%)$ and high mib-1 was observed in $93(81.6 \%)$ patients. Recurrence occurred in $22(19.3 \%)$, and cancer-correlated death occurred in $21(18.4 \%)$, of 114 patients. Median follow-up for the RFS analysis was 35 months and that for OS was 42.5 months. The cut-point 
Fig. 1 Immunohistochemical detection of intratumoral (i) TILs $(C D 20+$, CD $38+$, and $\mathrm{CD} 138+$ ) in triple-negative breast cancer (TNBC). a and b Low vs high expression of iCD20+ TILs in patients' specimens. $\mathbf{c}$ and $\mathbf{d}$ Low vs high expression of iCD38 + TILs in patients' specimens. e and f Low vs high expression of iCD138+ TILs in TNBC. (original magnification $\times 400$ )
A

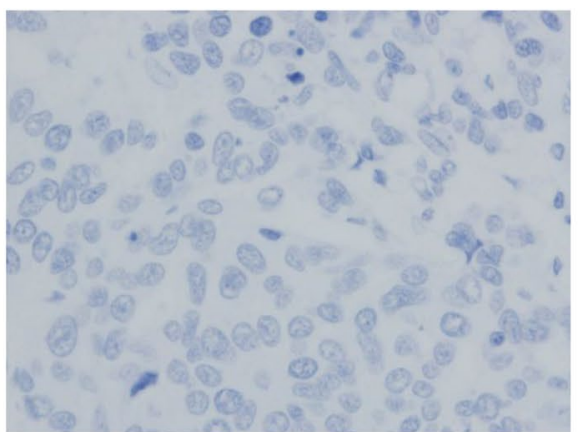

Low iCD20

C

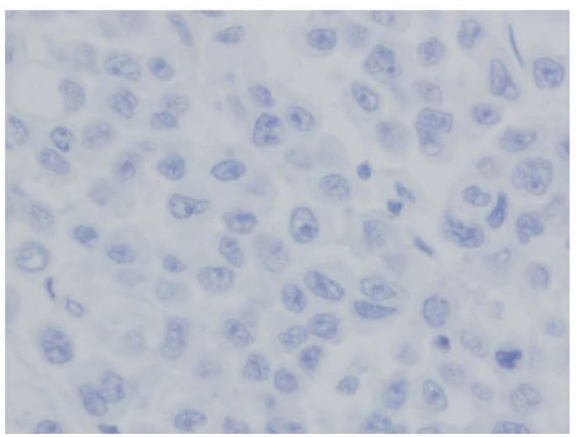

Low iCD38

E

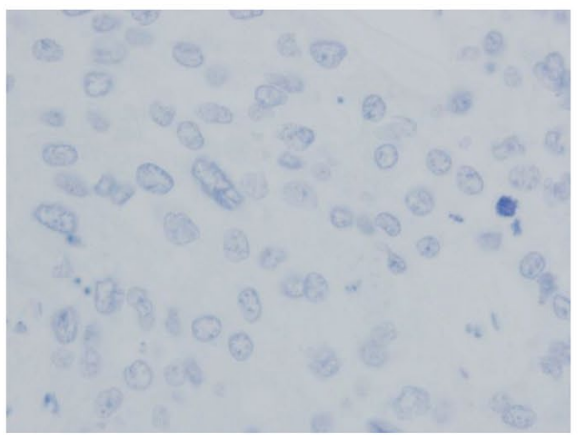

Low iCD138
B

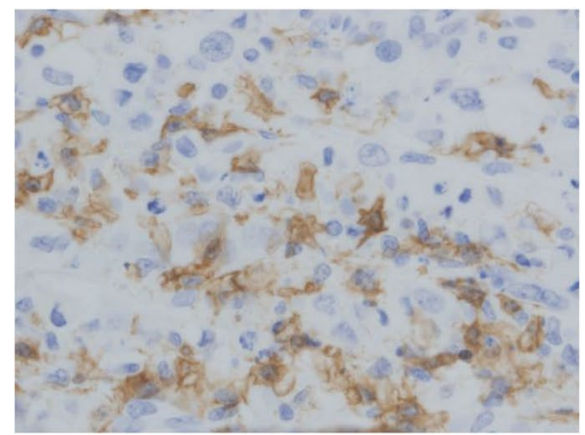

High iCD20

D

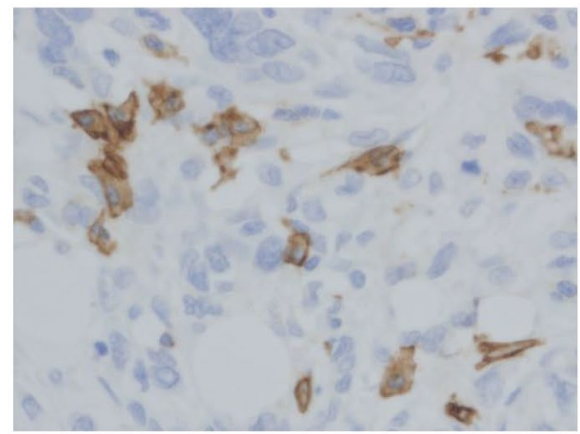

High iCD38

F

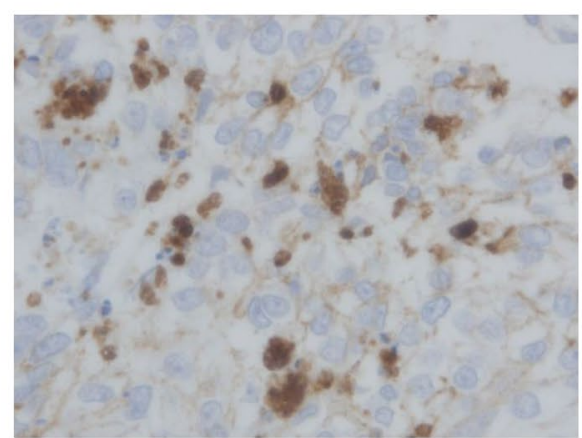

High iCD138 value for $\mathrm{iCD} 20$ + was $1, \mathrm{sCD} 20$ + was $61, \mathrm{iCD} 38$ + was 4 , $\mathrm{sCD} 38$ + was 39.5 , iCD138 + was 10.5 , and $\mathrm{sCD} 138$ + was 35 . The clinicopathological characteristics of the 114 TNBC patients in terms of $\mathrm{i}$ and s CD20+TILs, CD38 + TILs and CD138 + TILs are presented in Table 1. A low density of iCD20+ TILs was significantly correlated with a lower density of iTILs $(p=0.002)$ and sTILs $(p=0.004)$. However, there was no significant association between a predominance of iCD38 + TILs and iCD138 + TILs and clinicopathological characteristics. A predominance of sCD20 + TILs, sCD38 + TILs, and sCD138+ TILs was associated with higher sTILs expression $(p<0.001, p<0.001$, and $p=0.011$, respectively). A predominance of sCD20 + TILs showed a significant difference for iTILs $(p=0.009)$, while sCD138 + TILs were associated with mib-1 $(p=0.032)$ expression. In addition, the presence of TLS was significantly associated with high iCD20, iCD138, sC20, and $\operatorname{sCD} 138(p=0.008, p=0.023, p<0.001$, and $p=0.036$ ).

Correlations among prognosis and clinicopathological factors, unstained TILs, CD20 + TILs, CD38 + TILs, and CD138 + TILs are listed in Table 2. Multivariate Cox regression analysis was applied for all clinicopathological factors that were significantly correlated with survival in univariate analysis for RFS and OS. The results revealed that 
Fig. 2 Stromal(s) TILs $(\mathrm{CD} 20+, \mathrm{CD} 38+$, and $\mathrm{CD} 138+$ ) in triple-negative breast cancer (TNBC). Immunohistochemical staining representing low (a) and high (b) SCD20 + TILs density; low (c) and (d) high sCD38 + TILs density; and low (e) and high (f) sCD138 + TILs density in TNBC. (original magnification $\times 400)$
A

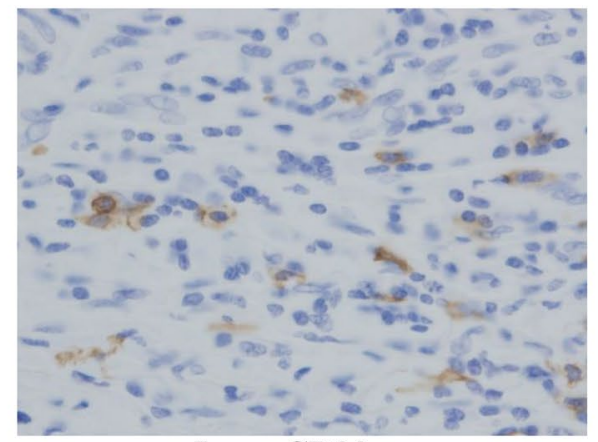

Low sCD20

C

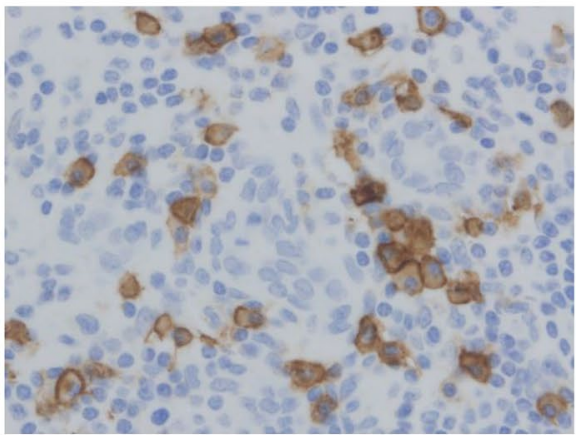

Low sCD38

E

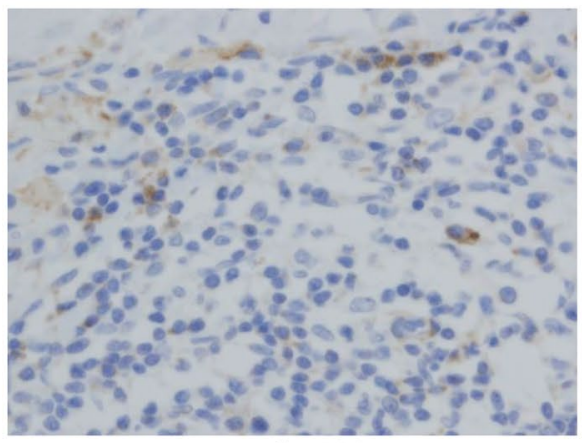

Low sCD138
B

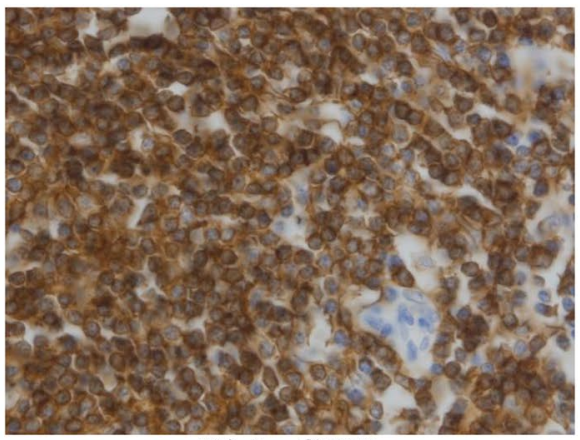

High sCD20

D

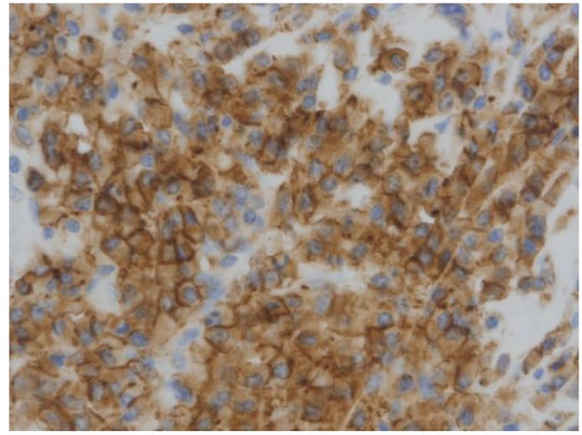

High sCD38

F

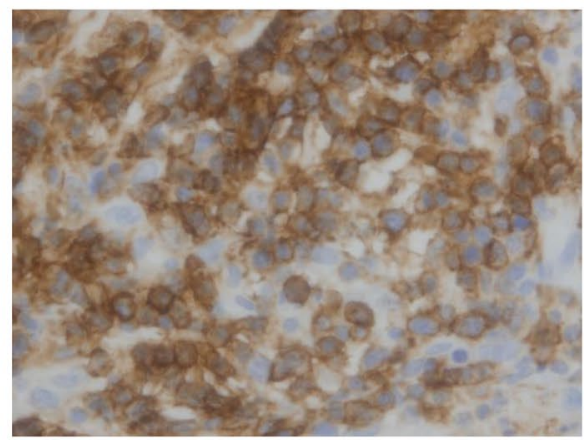

High sCD138 larger tumor size was related to poorer RFS ( $\mathrm{HR}=2.616$, 95\% CI 1.082-6.330, $p=0.033)$ and OS (HR $=2.849,95 \%$ CI 1.166-6.962, $p=0.022$ ). sCD20 + TILs was significant for RFS with HRs of 0.363 (95\% CI 0.136-0.969, $p=0.043$ ) and OS with HRs of 0.330 (95\% CI 0.124-0.880, $p=0.027$ ). SCD38 + TILs were significantly correlated with favorable RFS (HR $=0.323,95 \%$ CI 0.109-0.960, $p=0.042)$, but not OS (HR $=0.342,95 \%$ CI $0.113-1.037, p=0.058)$.

We analyzed survival in terms of the significant rates of CD20 + TILs, CD38 + TILs, and CD138 + TILs using the Kaplan-Meier method and log-rank test. TNBCs classified as high iCD20 + TILs, sCD20 + TILs, and sCD38 + TILs had significantly improved RFS compared to those with low expressions of iCD20 + TILs, sCD20 + TILs, and sCD38+ TILs ( $p=0.025, p=0.006, p=0.008$, respectively; Fig. 3a, b, d). Nevertheless, no significant association was found between the density of iCD38 + TILs $(p=0.055)$, iCD138+ TILs $(p=0.718)$, and SCD138+ TILs $(p=0.066)$ and RFS (Fig. 3c, e, f). A high density of iCD20+ TILs, sCD20 + TILs and SCD38 + TILs was significantly related to better OS compared with a low density of iCD20+TILs, sCD20+ TILs, and sCD38+ TILs ( $p=0.026, p=0.004$, and 


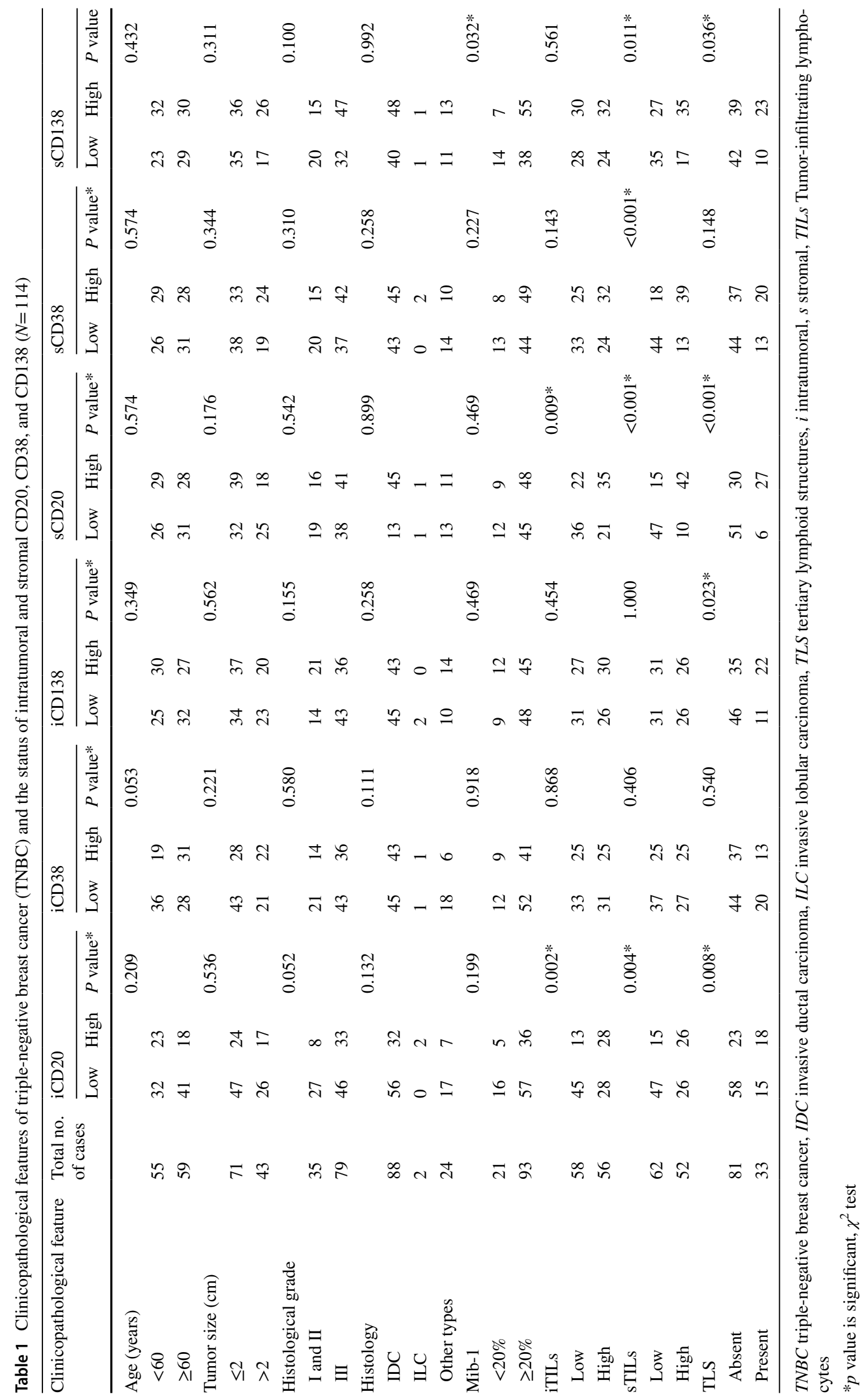


Table 2 Relapse-free survival (RFS) and overall survival (OS) rate according to Univariate and Multivariate Cox regression analyses of prognostic factors of 114 patients with triple-negative breast cancer (TNBC)

\begin{tabular}{|c|c|c|c|c|c|c|c|c|}
\hline \multirow{3}{*}{$\begin{array}{l}\text { Clinicopathologi- } \\
\text { cal feature }\end{array}$} & \multicolumn{4}{|l|}{ RFS } & \multicolumn{4}{|l|}{ OS } \\
\hline & \multicolumn{2}{|c|}{ Univariate analysis } & \multicolumn{2}{|c|}{ Multivariate analysis } & \multicolumn{2}{|c|}{ Univariate analysis } & \multicolumn{2}{|c|}{ Multivariate analysis } \\
\hline & HR $(95.0 \%$ CI) & $P$ value* & HR $(95.0 \%$ CI $)$ & $P$ value* & HR $(95.0 \%$ CI) & $P$ value* & HR $(95.0 \%$ CI) & $P$ value* \\
\hline Age (<60 vs. $\geq 60)$ & $\begin{array}{l}0.523(0.209- \\
1.308)\end{array}$ & 0.166 & & & $\begin{array}{l}0.564(0.225- \\
1.413)\end{array}$ & 0.222 & & \\
\hline $\begin{array}{l}\text { Tumor size }(2 \mathrm{~cm} \\
\text { vs. }>2 \mathrm{~cm})\end{array}$ & $\begin{array}{l}2.491(1.051- \\
5.905)\end{array}$ & $0.038^{*}$ & $\begin{array}{l}2.616(1.082- \\
6.330)\end{array}$ & $0.033^{*}$ & $\begin{array}{l}2.710(1.139- \\
6.452)\end{array}$ & $0.024 *$ & $\begin{array}{l}2.849(1.166- \\
6.962)\end{array}$ & $0.022 *$ \\
\hline $\begin{array}{l}\text { Histological grade } \\
\text { (I, II vs. III) }\end{array}$ & $\begin{array}{l}2.666(0.785- \\
9.055)\end{array}$ & 0.116 & & & $\begin{array}{l}2.582(0.760- \\
8.770)\end{array}$ & 0.128 & & \\
\hline $\begin{array}{l}\text { Histology (IDC vs. } \\
\text { ILC, other types) }\end{array}$ & $\begin{array}{l}0.590(0.173- \\
2.007)\end{array}$ & 0.398 & & & $\begin{array}{l}0.600(0.176- \\
2.040)\end{array}$ & 0.413 & & \\
\hline $\begin{array}{l}\text { Mib-1 (<20\% vs. } \\
\geq 20 \%)\end{array}$ & $\begin{array}{l}2.176(0.500- \\
9.464)\end{array}$ & 0.300 & & & $\begin{array}{l}2.379(0.542- \\
10.448)\end{array}$ & 0.251 & & \\
\hline $\begin{array}{l}\text { TLS (absent vs. } \\
\text { present) }\end{array}$ & $\begin{array}{l}0.776(0.283- \\
2.124)\end{array}$ & 0.621 & & & $\begin{array}{l}0.772(0.283- \\
2.112)\end{array}$ & 0.615 & & \\
\hline $\begin{array}{l}\text { iTILs (low vs. } \\
\text { high) }\end{array}$ & $\begin{array}{l}0.598(0.244- \\
1.468)\end{array}$ & 0.262 & & & $\begin{array}{l}0.565(0.230- \\
1.390)\end{array}$ & 0.214 & & \\
\hline $\begin{array}{l}\text { sTILs (low vs. } \\
\text { high) }\end{array}$ & $\begin{array}{l}0.330(0.111- \\
0.988)\end{array}$ & $0.048^{*}$ & $\begin{array}{l}0.563(0.169- \\
1.877)\end{array}$ & 0.349 & $\begin{array}{l}0.332(0.111- \\
0.992)\end{array}$ & $0.048^{*}$ & $\begin{array}{l}0.569(0.168- \\
1.933)\end{array}$ & 0.366 \\
\hline $\begin{array}{l}\text { iCD20 (low vs. } \\
\text { high) }\end{array}$ & $\begin{array}{l}0.273(0.080- \\
0.928)\end{array}$ & $0.037 *$ & $\begin{array}{l}0.373(0.106- \\
1.310)\end{array}$ & 0.124 & $\begin{array}{l}0.273(0.080- \\
0.929)\end{array}$ & $0.038^{*}$ & $\begin{array}{l}0.377(0.108- \\
1.320)\end{array}$ & 0.127 \\
\hline $\begin{array}{l}\text { sCD20 (low vs. } \\
\text { high) }\end{array}$ & $\begin{array}{l}0.287(0.110- \\
0.746)\end{array}$ & $0.010^{*}$ & $\begin{array}{l}0.363(0.136- \\
0.969)\end{array}$ & $0.043 *$ & $\begin{array}{l}0.265(0.102- \\
0.690)\end{array}$ & $0.007 *$ & $\begin{array}{l}0.330(0.124- \\
0.880)\end{array}$ & $0.027 *$ \\
\hline $\begin{array}{l}\text { iCD38 (low vs. } \\
\text { high) }\end{array}$ & $\begin{array}{l}0.388(0.142- \\
1.061)\end{array}$ & 0.065 & & & $\begin{array}{l}0.396(0.145- \\
1.083)\end{array}$ & 0.071 & & \\
\hline $\begin{array}{l}\text { sCD38 (low vs. } \\
\text { high) }\end{array}$ & $\begin{array}{l}0.280(0.102- \\
0.764)\end{array}$ & $0.013^{*}$ & $\begin{array}{l}0.323(0.109- \\
0.960)\end{array}$ & $0.042 *$ & $\begin{array}{l}0.292(0.107- \\
0.799)\end{array}$ & $0.017 *$ & $\begin{array}{l}0.342(0.113- \\
1.037)\end{array}$ & 0.058 \\
\hline $\begin{array}{l}\text { iCD138 (low vs. } \\
\text { high) }\end{array}$ & $\begin{array}{l}1.173(0.492- \\
2.794)\end{array}$ & 0.719 & & & $\begin{array}{l}1.193(0.502- \\
2.838)\end{array}$ & 0.689 & & \\
\hline $\begin{array}{l}\text { sCD138 (low vs. } \\
\text { high) }\end{array}$ & $\begin{array}{l}0.446(0.184- \\
1.082)\end{array}$ & 0.074 & & & $\begin{array}{l}0.455(0.187- \\
1.105)\end{array}$ & 0.082 & & \\
\hline
\end{tabular}

$T N B C$ triple-negative breast cancer, $R F S$ relapse-free survival, $O S$ overall survival, $H R$ hazard ratio, $C I$ confidence interval, $I D C$ invasive ductal carcinoma, $I L C$ invasive lobular carcinoma, TLS tertiary lymphoid structures, $i$ intratumoral, $s$ stromal, TILs tumor-infiltrating lymphocytes

${ }^{*} p$ value is significant

$p=0.011$, respectively; Fig. $4 \mathrm{a}, \mathrm{b}, \mathrm{d})$. In contrast, no correlation between the status of iCD38 + TILs, iCD138 + TILs, and sCD138 + TILs and OS was observed $(p=0.061$, $p=0.688$, and $p=0.074$, respectively; Fig. $4 \mathrm{c}, \mathrm{e}, \mathrm{f}$ ).

\section{Discussion}

We found that TNBC patients with a significant increase in sCD20 + TILs had a favorable prognosis in terms of both RFS and OS. Previous studies provided evidence that significant expression of TILs-B was correlated with favorable prognosis in several organs [1, 2, 6, 27-29]. A high distribution of CD20 + TILs in epithelioid mesothelioma was correlated with good prognosis [30]. Further, CD20 + TILs had positive associations in high grade serous ovarian cancer [5], but not in other histological subtypes
[31]. Similar results have been confirmed in several organs such as ovarian, gastric, and colorectal cancers [3, 32, 33]. Therefore, it is possible to predict that in cancers of certain organs, expression of an immune suppressive substance from TIL-B supports anti-tumor cells. However, the limited data on the role of TIL-B in breast cancer is still being debated. Mohammed et al. reported that the proportion of CD20 + TILs did not correlate with outcomes in primary breast cancer [15]. In contrast, previous studies reported on the role of CD20 + TILs in breast cancer and found a positive prognostic effect [7, 8, 10, 11, 34]. In multivariable analysis, Brown et al. reported that only CD20 + TILs in breast cancer were associated with a significant complete pathologic response (pCR) [35]. Moreover, these results were independent of other variables such as age, tumor size, nuclear grade, lymph node status, ER, PgR, HER2 status and ki67 index. Song et al. also reported that a high density of CD20+ TILs 

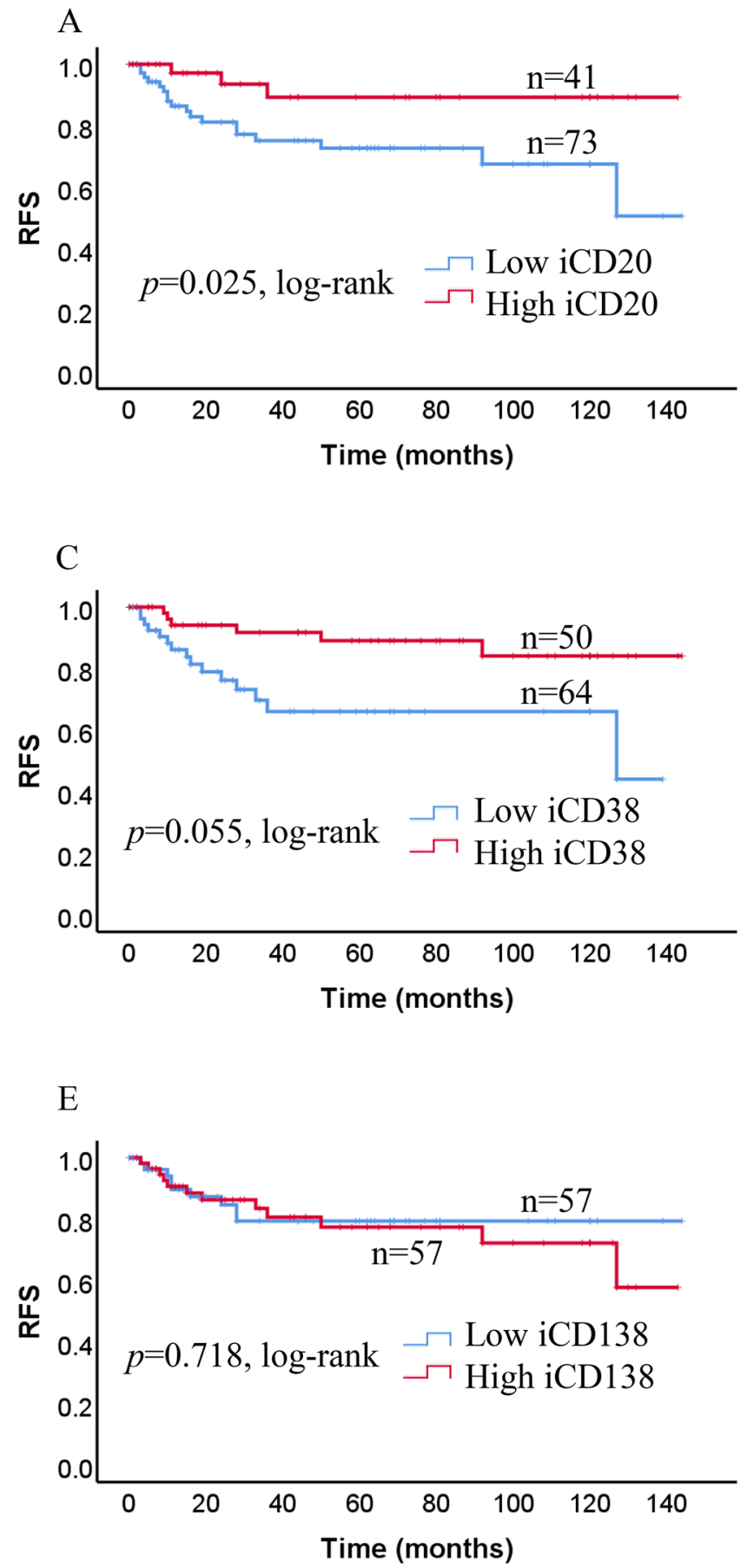

Fig. 3 Kaplan-Meier estimates of relapse-free survival (RFS) in all patients based on i and s TILs (CD20+, CD38+ and CD138+) expression. Kaplan-Meier analysis of RFS in low and high expres-

was a significant predictor of pCR in a total of 108 TNBC patients treated with neoadjuvant chemotherapy [9]. Xu et al. recently reported in a multivariate analysis of 102 IDC patients that a high level of CD20 + TILs showed improved OS, but not good disease-free survival (DFS) [12]. Furthermore, in an extensive number of invasive breast cancers,
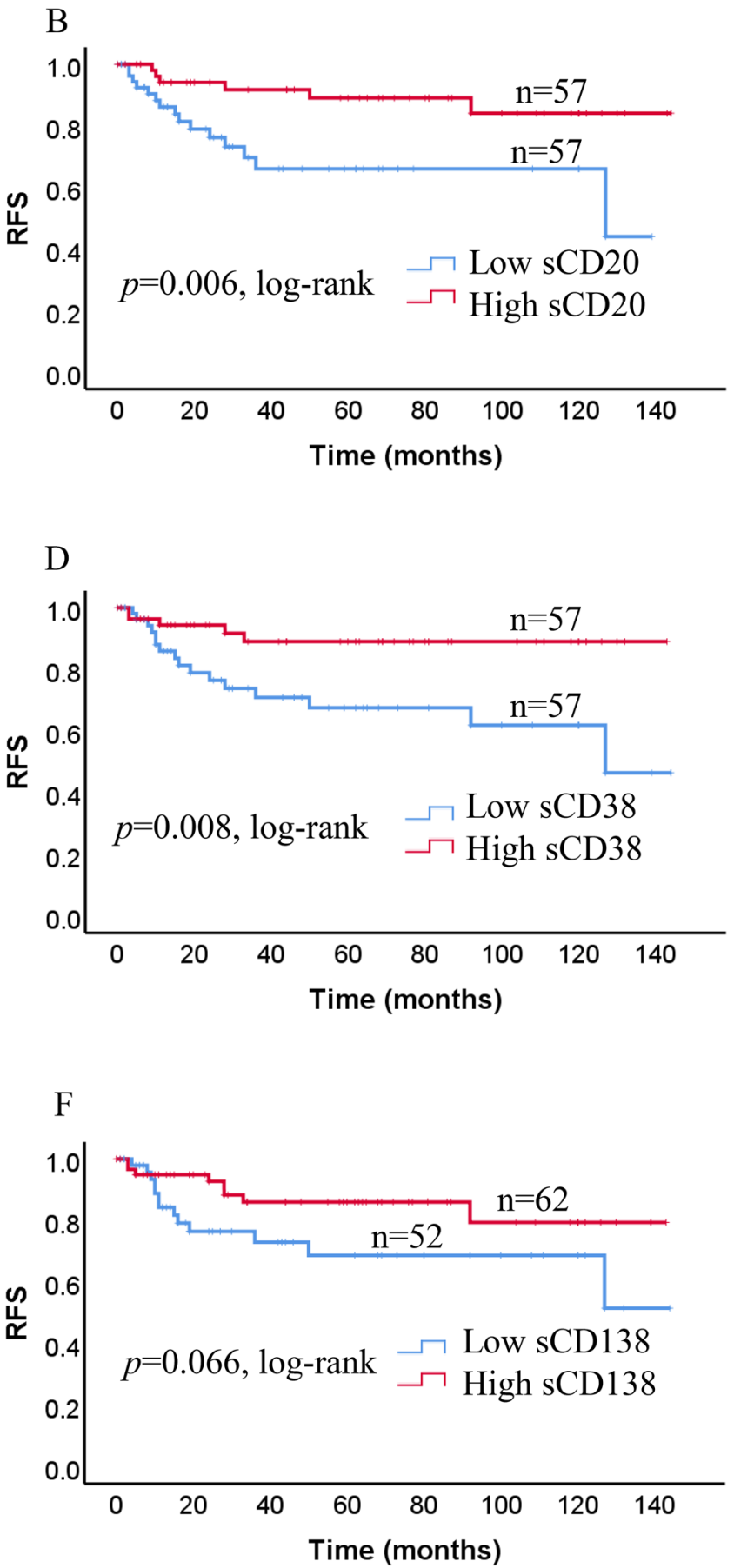

sion curves of a iCD20+TILs, $\mathbf{b}$ sCD20+TILs, $\mathbf{c}$ iCD38+TILs, $\mathbf{d}$ sCD38 + TILs, e iCD138 + TILs, and $\mathbf{f}$ sCD138 + TILs

Mahmoud et al. observed predominance of CD20+TILs was significantly correlated with favorable prognosis in both breast cancer-specific survival and disease-free interval [8]. However, these two reports used tissue microarrays that can underestimate TIL-B compared with full sections. The present study evaluated whole sections from each case 

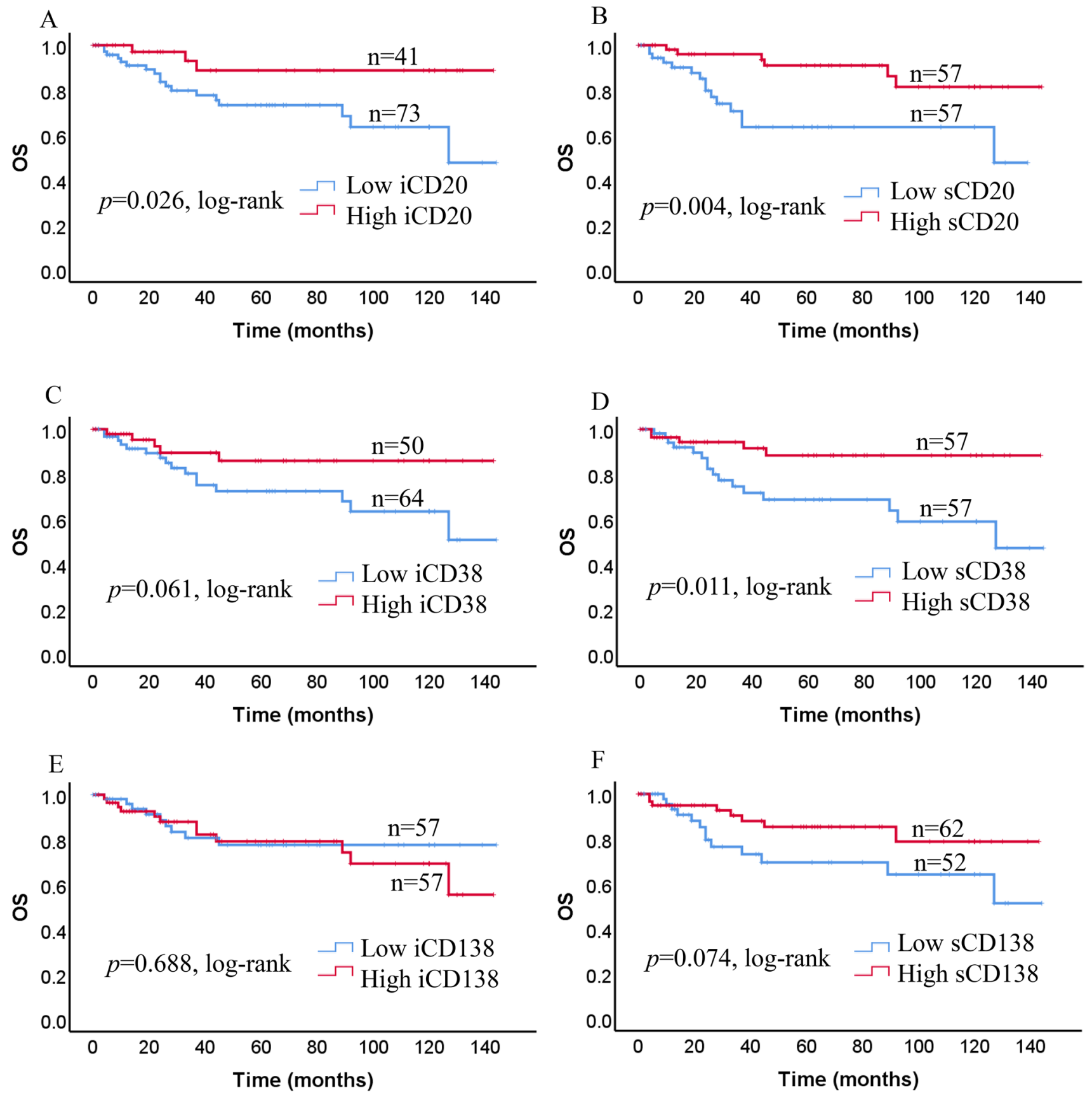

Fig. 4 Kaplan-Meier curves of overall survival (OS) in triple-negative breast cancer (TNBC). OS based on high and low expression of iCD20 + TILs (a), sCD20 + TILs (b), iCD38 + TILs (c), sCD38 + TILs (d), iCD138 + TILs (e), and sCD138 + TILs (f) in all patients with TNBC

for which iCD20 + and sCD20+ TILs correlated with good prognosis and TILs-B assessed by CD20 + indicated promotion of an immune reaction; therefore, $\mathrm{CD} 20+$ cells likely have an essential role in the tumor progression associated with TNBC prognosis.

In univariate analyses, we found that TNBC patients with a favorable prognosis in terms of both RFS and OS had a high density of sCD38 + TILs, but not CD138 + TILs. However, in multivariate analyses, we only observed that TNBC patients with an improved prognosis had an increased number of sCD38 + TILs in RFS. Only a few studies reported on the role of CD138+ TILs in cancers and they were correlated with negative prognosis. Lundgren et al. reported that a high density of CD20 + and CD138 + TILs was markedly associated with high grade ovarian cancer [36]. Univariate Cox regression analysis indicated that a high density of CD138 + TILs was correlated with poor disease-specific survival and 
OS. Similar to these findings, Bosisio et al. reported that melanomas with a high number of CD138 + TILs were associated with worse prognosis [4]. In contrast to our findings, Mohammed et al. reported that CD138 + TILs were negatively associated with RFS in ductal breast cancer in multivariate analysis [15]. Milligy et al. reported that a high density of CD138 + TILs among TILs in patients correlated with shorter RFS [14]. However, several studies showed an improved prognostic influence of CD138 + TILs in melanoma, esophageal cancer, gastric cancer, and colorectal cancer [1, 3, 28, 37]. As the results differ among these reports, it is difficult to evaluate CD138 + . In our study, CD138 + stained not only TILs-B, but also epithelial and stromal cells. Due to estimation difficulty, there was no significant difference in iCD138 + and sCD138 + TILs in our study. Tumor epithelium and stromal CD138 + reactions in breast cancer have been reported previously [34, 38]. Therefore, it is not unexpected that different prognostic results have been reported for CD138 + . Further, similar to CD138 +, there are reports of CD38 + TILs, a marker of not only plasma cells, but also defining naïve memory $\mathrm{B}$ cells, in several solid tumors. The elucidating role of the CD38 marker may be associated with the development and immune escape within solid tumors and is a relatively new concept. The limited data in melanoma, glioma, esophageal, cervical, and lung cancers indicate an immunosuppressive role for CD38 [6, 39-43]. In these solid tumors, CD38 seems to be activated as a tumor-progressing factor. However, the role of CD38 in solid tumors is likely to be more complex than first considered. Recently, CD38 + TILs have been associated with longer survival in urinary bladder cancer [44]. Similar to our findings from whole section examinations, Yeong et al. recently used the tissue microarray method and multivariate analysis to clarify that TNBC patients with CD38 + TILs had significantly better DFS, but not OS [34]. Therefore, these results also imply that increased proliferation of CD38 + may have an effect on the clinical outcome in TNBC.

CD38 was primarily reported as a lymphocyte marker $[45,46]$, but knowledge about CD38 has advanced [47, 48]. It is almost ubiquitously expressed on multiple immune cells, including not only B cells, but also $\mathrm{T}$ cells, NK cells, macrophages and dendritic cells $[49,50]$. These studies have shown the detection of CD38 + on IHC-stained tissue alone, leads to under or overestimation. Therefore, we observed CD $38+\mathrm{B}$ cells on both $\mathrm{H} \& \mathrm{E}$ slides and IHC-stained slides to generate greater intra- and inter-observer agreement and reproducibility. However, it is possible that we may not have completely excluded CD38 expression on cells within the tumor microenvironment, such as $\mathrm{T}$ cells, macrophages and dendritic cells. While CD38 expression on B cells remains the main theme of current research, more data is beginning to be gathered concerning the role of CD38 expression on tumor cells. Additional research is expected to completely elucidate its function and potential in TNBC.

TLS are highly constructed aggregates of lymphoid cells that resemble lymph nodes [18]. It has been suggested that TLS support anti-tumor reactions involving the combined responses of both B-cell activation and antibody-production by plasma cells [17]. Previous studies reported the close correlation of TLS in tumors of the ovary [18], breast [51, 52], metastatic melanoma [28], and non-small cell lung cancer [53]. Further, Lee et al. reported that TLS is an important factor in the pathological complete response in TNBC [51]. Further, Seow et al. reported that TNBC with a high density of CD20 + and CD $38+$ B cells were associated with TLS [54]. However, tumor areas were selected for tissue microarray (TMA) construction in their research. The limitation of TLS detection on TMA alone can lead to an incorrect evaluation, as compared to detection of TLS on whole slide sections. Alhough only certified in a limited cohort, our findings also suggest that higher densities of CD20 and CD138 + cells were also associated with TLS in TNBC. However, evidence for this was not confirmed by multivariate analysis. More research using a larger cohort should be performed, not only to establish the proportion and frequencies of TLS in TNBC, but also to clarify the association between TLS and B cells in forming an anti-tumoral microenvironment for TNBC.

\section{Conclusions}

The present study demonstrated that a higher density of sCD20 + TILs was significantly related to favorable prognosis in both RFS and OS. Increased SCD38 + TILs in TNBC were correlated with a significantly favorable prognosis in RFS. These results indicate that TILs-B may have an improved prognostic influence on clinical outcomes in TNBC.

Acknowledgements All authors thank T. Yazawa, C. Matsuyama and A. Shimizu for their advice, technical assistance with IHC staining.

Author contributions $\mathrm{HK}$ and TJ contributed equally to this work; AA collected clinical information; HK and TJ reviewed the pathological diagnosis; HK and TJ analyzed the data and wrote the manuscript; RY, $\mathrm{AK}, \mathrm{OH}$ and $\mathrm{BE}$ made critical revisions of the manuscript; $\mathrm{HK}$ and $\mathrm{TJ}$ designed the study; AM gave the final approval of the manuscript for publication.

\section{Compliance with ethical standards}

Conflict of interest The authors declare that they have no conflicts of interest. 
Open Access This article is licensed under a Creative Commons Attribution 4.0 International License, which permits use, sharing, adaptation, distribution and reproduction in any medium or format, as long as you give appropriate credit to the original author(s) and the source, provide a link to the Creative Commons licence, and indicate if changes were made. The images or other third party material in this article are included in the article's Creative Commons licence, unless indicated otherwise in a credit line to the material. If material is not included in the article's Creative Commons licence and your intended use is not permitted by statutory regulation or exceeds the permitted use, you will need to obtain permission directly from the copyright holder. To view a copy of this licence, visit http://creativecommons.org/licenses/by/4.0/.

\section{References}

1. Fristedt R, Borg D, Hedner C, Berntsson J, Nodin B, Eberhard J, et al. Prognostic impact of tumour-associated B cells and plasma cells in oesophageal and gastric adenocarcinoma. J Gastrointest Oncol. 2016;7:848-59. https://doi.org/10.21037/jgo.2016.11.07.

2. Hennequin A, Derangere V, Boidot R, Apetoh L, Vincent J, Orry $\mathrm{D}$, et al. Tumor infiltration by Tbet+ effector T cells and CD20+ $\mathrm{B}$ cells is associated with survival in gastric cancer patients. Oncoimmunology. 2015;5:e1054598. https://doi.org/10.1080/21624 02X.2015.1054598.

3. Berntsson J, Nodin B, Eberhard J, Micke P, Jirstrom K. Prognostic impact of tumour-infiltrating B cells and plasma cells in colorectal cancer. Int J Cancer. 2016;139:1129-39. https://doi.org/10.1002/ ijc. 30138.

4. Bosisio FM, Wilmott JS, Volders N, Mercier M, Wouters J, Stas $\mathrm{M}$, et al. Plasma cells in primary melanoma. Prognostic significance and possible role of IgA. Mod Pathol. 2016;29:347-58. https://doi.org/10.1038/modpathol.2016.28.

5. Milne K, Kobel M, Kalloger SE, Barnes RO, Gao D, Gilks CB, et al. Systematic analysis of immune infiltrates in high-grade serous ovarian cancer reveals CD20, FoxP3 and TIA- 1 as positive prognostic factors. PLoS ONE. 2009;4:e6412. https://doi. org/10.1371/journal.pone.0006412.

6. Lohr M, Edlund K, Botling J, Hammad S, Hellwig B, Othman A, et al. The prognostic relevance of tumour-infiltrating plasma cells and immunoglobulin kappa $\mathrm{C}$ indicates an important role of the humoral immune response in non-small cell lung cancer. Cancer Lett. 2013;333:222-8. https://doi.org/10.1016/j.canle t.2013.01.036.

7. Mohammed ZM, Going JJ, Edwards J, Elsberger B, Doughty JC, McMillan DC. The relationship between components of tumour inflammatory cell infiltrate and clinicopathological factors and survival in patients with primary operable invasive ductal breast cancer. Br J Cancer. 2012;107:864-73. https://doi.org/10.1038/ bjc. 2012.347.

8. Mahmoud SM, Lee AH, Paish EC, Macmillan RD, Ellis IO, Green AR. The prognostic significance of B lymphocytes in invasive carcinoma of the breast. Breast Cancer Res Treat. 2012;132:545-53. https://doi.org/10.1007/s10549-011-1620-1.

9. Song IH, Heo SH, Bang WS, Park HS, Park IA, Kim YA, et al. Predictive value of tertiary lymphoid structures assessed by high endothelial venule counts in the neoadjuvant setting of triple-negative breast cancer. Cancer Res Treat. 2017;49:399-407. https:// doi.org/10.4143/crt.2016.215.

10. Schmidt M, Bohm D, von Torne C, Steiner E, Puhl A, Pilch H, et al. The humoral immune system has a key prognostic impact in node-negative breast cancer. Cancer Res. 2008;68:5405-13. https ://doi.org/10.1158/0008-5472.CAN-07-5206.

11. Schmidt M, Micke P, Gehrmann M, Hengstler JG. Immunoglobulin kappa chain as an immunologic biomarker of prognosis and chemotherapy response in solid tumors. Oncoimmunology. 2012;1:1156-8. https://doi.org/10.4161/onci.21653.

12. Xu Y, Lan S, Zheng Q. Prognostic significance of infiltrating immune cell subtypes in invasive ductal carcinoma of the breast. Tumori. 2018;104:196-201. https://doi.org/10.5301/tj.5000624.

13. Mohammed ZM, Going JJ, Edwards J, McMillan DC. The role of the tumour inflammatory cell infiltrate in predicting recurrence and survival in patients with primary operable breast cancer. Cancer Treat Rev. 2012;38:943-55. https://doi.org/10.1016/j. ctrv.2012.04.011.

14. Miligy IM, Toss MS, Khout H, Whisker L, Burrell HC, Ellis IO, et al. Surgical management of ductal carcinoma in situ of the breast: a large retrospective study from a single institution. Breast J. 2019;25:1143-53. https://doi.org/10.1111/tbj.13425.

15. Mohammed ZM, Going JJ, Edwards J, Elsberger B, McMillan DC. The relationship between lymphocyte subsets and clinico-pathological determinants of survival in patients with primary operable invasive ductal breast cancer. Br J Cancer. 2013;109:1676-84. https://doi.org/10.1038/bjc.2013.493.

16. Sarvaria A, Madrigal JA, Saudemont A. B cell regulation in cancer and anti-tumor immunity. Cell Mol Immunol. 2017;14:66274. https://doi.org/10.1038/cmi.2017.35.

17. Dieu-Nosjean MC, Goc J, Giraldo NA, Sautes-Fridman C, Fridman WH. Tertiary lymphoid structures in cancer and beyond. Trends Immunol. 2014;35(11):571-8. https://doi.org/10.1016/j. it.2014.09.006.

18. Kroeger DR, Milne K, Nelson BH. Tumor-infiltrating plasma cells are associated with tertiary lymphoid structures, cytolytic T-cell responses, and superior prognosis in ovarian cancer. Clin Cancer Res. 2016;22(12):3005-15. https://doi. org/10.1158/1078-0432.CCR-15-2762.

19. Teillaud JL, Dieu-Nosjean MC. Tertiary lymphoid structures: an anti-tumor school for adaptive immune cells and an antibody factory to fight cancer? Front Immunol. 2017;8:830. https://doi. org/10.3389/fimmu.2017.00830.

20. Sorlie T, Tibshirani R, Parker J, Hastie T, Marron JS, Nobel A, et al. Repeated observation of breast tumor subtypes in independent gene expression data sets. Proc Natl Acad Sci U S A. 2003;100:8418-23. https://doi.org/10.1073/pnas.0932692100.

21. Allison KH, Hammond MEH, Dowsett M, McKernin SE, Carey LA, Fitzgibbons PL, et al. Estrogen and progesterone receptor testing in breast cancer: ASCO/CAP guideline update. J Clin Oncol. 2020. https://doi.org/10.1200/JCO.19.02309.

22. Wolff AC, Hammond MEH, Allison KH, Harvey BE, Mangu PB, Bartlett JMS, et al. Human epidermal growth factor receptor 2 testing in breast cancer: American Society of Clinical Oncology/College of American Pathologists Clinical Practice Guideline Focused Update. Arch Pathol Lab Med. 2018;142:1364-82. https://doi.org/10.5858/arpa.2018-0902-SA.

23. Tashima R, Nishimura R, Osako T, Nishiyama Y, Okumura Y, Nakano M, et al. Evaluation of an OPTIMAL CUT-OFF POInt for the Ki-67 index as a prognostic factor in primary breast cancer: a retrospective study. PLoS ONE. 2015;10:e0119565. https://doi.org/10.1371/journal.pone.0119565.

24. Hendry S, Salgado R, Gevaert T, Russell PA, John T, Thapa $\mathrm{B}$, et al. Assessing tumor-infiltrating lymphocytes in solid tumors: a practical review for pathologists and proposal for a standardized method from theInternational Immuno-oncology Biomarkers Working Group: Part 1: assessing the host immune response, TILs in invasive breast carcinoma and ductal carcinoma in situ, metastatic tumor deposits and areas for further research. Adv Anat Pathol. 2017;24:235-51. https://doi. org/10.1097/PAP.0000000000000162.

25. Loi S, Drubay D, Adams S, Pruneri G, Francis PA, LacroixTriki M, et al. Tumor-infiltrating lymphocytes and prognosis: a pooled individual patient analysis of early-stage triple-negative 
breast cancers. J Clin Oncol. 2019;37:559-69. https://doi. org/10.1200/JCO.18.01010.

26. Mahmoud SM, Paish EC, Powe DG, Macmillan RD, Grainge MJ, Lee AH, et al. Tumor-infiltrating CD8+ lymphocytes predict clinical outcome in breast cancer. J Clin Oncol. 2011;29(15):1949-55. https://doi.org/10.1200/ JCO.2010.30.5037.

27. Wouters MCA, Nelson BH. Prognostic significance of tumor-infiltrating B cells and plasma cells in human cancer. Clin Cancer Res. 2018;24:6125-35. https://doi.org/10.1158/1078-0432.CCR-18-1481.

28. Erdag G, Schaefer JT, Smolkin ME, Deacon DH, Shea SM, Dengel LT, et al. Immunotype and immunohistologic characteristics of tumor-infiltrating immune cells are associated with clinical outcome in metastatic melanoma. Cancer Res. 2012;72:1070-80. https://doi.org/10.1158/0008-5472.CAN-11-3218.

29. Brunner SM, Itzel T, Rubner C, Kesselring R, Griesshammer E, Evert $\mathrm{M}$, et al. Tumor-infiltrating B cells producing antitumor active immunoglobulins in resected HCC prolong patient survival. Oncotarget. 2017;8:71002-11. https://doi.org/10.18632/oncotarget.20238.

30. Chee SJ, Lopez M, Mellows T, Gankande S, Moutasim KA, Harris $\mathrm{S}$, et al. Evaluating the effect of immune cells on the outcome of patients with mesothelioma. Br J Cancer. 2017;117:1341-8. https://doi.org/10.1038/bjc.2017.269.

31. Iglesia MD, Vincent BG, Parker JS, Hoadley KA, Carey LA, Perou CM, et al. Prognostic B-cell signatures using mRNA-seq in patients with subtype-specific breast and ovarian cancer. Clin Cancer Res. 2014;20:3818-29. https://doi.org/10.1158/10780432.CCR-13-3368.

32. Dong HP, Elstrand MB, Holth A, Silins I, Berner A, Trope CG, et al. NK- and B-cell infiltration correlates with worse outcome in metastatic ovarian carcinoma. Am J Clin Pathol. 2006;125:451-8.

33. Wiksten JP, Lundin J, Nordling S, Lundin M, Kokkola A, von Boguslawski K, et al. Epithelial and stromal syndecan-1 expression as predictor of outcome in patients with gastric cancer. Int $\mathbf{J}$ Cancer. 2001;95:1-6. https://doi.org/10.1002/1097-0215(20010 120)95:13.0.CO;2-5.

34. Yeong J, Lim JCT, Lee B, Li H, Chia N, Ong CCH, et al. High densities of tumor-associated plasma cells predict improved prognosis in triple negative breast cancer. Front Immunol. 2018;9:1209. https://doi.org/10.3389/fimmu.2018.01209.

35. Brown JR, Wimberly H, Lannin DR, Nixon C, Rimm DL, Bossuyt V. Multiplexed quantitative analysis of CD3, CD8, and CD20 predicts response to neoadjuvant chemotherapy in breast cancer. Clin Cancer Res. 2014;20:5995-6005. https://doi.org/10.1158/10780432.CCR-14-1622.

36. Lundgren S, Berntsson J, Nodin B, Micke P, Jirstrom K. Prognostic impact of tumour-associated B cells and plasma cells in epithelial ovarian cancer. J Ovarian Res. 2016;9:21. https://doi. org/10.1186/s13048-016-0232-0.

37. Knief J, Reddemann K, Petrova E, Herhahn T, Wellner U, Thorns C. High density of tumor-infiltrating B-lymphocytes and plasma cells signifies prolonged overall survival in adenocarcinoma of the esophagogastric junction. Anticancer Res. 2016;36:5339-45.

38. Kind S, Jaretzke A, Buscheck F, Moller K, Dum D, Hoflmayer D, et al. A shift from membranous and stromal syndecan-1 (CD138) expression to cytoplasmic CD138 expression is associated with poor prognosis in breast cancer. Mol Carcinog. 2019;58:2306-15. https://doi.org/10.1002/mc.23119.

39. Chen L, Diao L, Yang Y, Yi X, Rodriguez BL, Li Y, et al. CD38mediated immunosuppression as a mechanism of tumor cell escape from PD-1/PD-L1 blockade. Cancer Discov. 2018;8(9):1156-75. https://doi.org/10.1158/2159-8290.CD-17-1033.

40. Ben Baruch B, Blacher E, Mantsur E, Schwartz H, Vaknine H, Erez N, et al. Stromal CD38 regulates outgrowth of primary melanoma and generation of spontaneous metastasis. Oncotarget. 2018;9(61):31797-811. https://doi.org/10.18632/oncotarget.25737.
41. Levy A, Blacher E, Vaknine H, Lund FE, Stein R, Mayo L. CD38 deficiency in the tumor microenvironment attenuates glioma progression and modulates features of tumor-associated microglia/ macrophages. Neuro Oncol. 2012;14(8):1037-49. https://doi. org/10.1093/neuonc/nos121.

42. Karakasheva TA, Waldron TJ, Eruslanov E, Kim SB, Lee JS, O'Brien S, et al. CD38-expressing myeloid-derived suppressor cells promote tumor growth in a murine model of esophageal cancer. Cancer Res. 2015;75(19):4074-85. https://doi. org/10.1158/0008-5472.CAN-14-3639.

43. Liao S, Xiao S, Chen H, Zhang M, Chen Z, Long Y, et al. CD38 enhances the proliferation and inhibits the apoptosis of cervical cancer cells by affecting the mitochondria functions. Mol Carcinog. 2017;56(10):2245-57. https://doi.org/10.1002/mc.22677.

44. Zirakzadeh AA, Sherif A, Rosenblatt R, Ahlen Bergman E, Winerdal M, Yang D, et al. Tumour-associated B cells in urothelial urinary bladder cancer. Scand J Immunol. 2020;91:e12830. https ://doi.org/10.1111/sji.12830.

45. Reinherz EL, Kung PC, Goldstein G, Levey RH, Schlossman SF. Discrete stages of human intrathymic differentiation: analysis of normal thymocytes and leukemic lymphoblasts of T-cell lineage. Proc Natl Acad Sci USA. 1980;77(3):1588-92. https://doi. org/10.1073/pnas.77.3.1588.

46. Terhorst C, van Agthoven A, LeClair K, Snow P, Reinherz E, Schlossman S. Biochemical studies of the human thymocyte cellsurface antigens T6, T9 and T10. Cell. 1981;23(3):771-80. https ://doi.org/10.1016/0092-8674(81)90441-4.

47. Malavasi F, Funaro A, Roggero S, Horenstein A, Calosso L, Mehta K. Human CD38: a glycoprotein in search of a function. Immunol Today. 1994;15(3):95-7. https://doi.org/10.1016/01675699(94)90148-1.

48. Quarona V, Zaccarello G, Chillemi A, Brunetti E, Singh VK, Ferrero $\mathrm{E}$, et al. CD38 and CD157: a long journey from activation markers to multifunctional molecules. Cytometry B Clin Cytom. 2013;84(4):207-17. https://doi.org/10.1002/cyto.b.21092.

49. Cockayne DA, Muchamuel T, Grimaldi JC, Muller-Steffner H, Randall TD, Lund FE, et al. Mice deficient for the ecto-nicotinamide adenine dinucleotide glycohydrolase CD38 exhibit altered humoral immune responses. Blood. 1998;92(4):1324-33.

50. Partida-Sanchez S, Goodrich S, Kusser K, Oppenheimer N, Randall TD, Lund FE. Regulation of dendritic cell trafficking by the ADP-ribosyl cyclase CD38: impact on the development of humoral immunity. Immunity. 2004;20(3):279-91. https://doi. org/10.1016/S1074-7613(04)00048-2.

51. Lee HJ, Park IA, Song IH, Shin SJ, Kim JY, Yu JH, et al. Tertiary lymphoid structures: prognostic significance and relationship with tumour-infiltrating lymphocytes in triple-negative breast cancer. J Clin Pathol. 2016;69(5):422-30. https://doi.org/10.1136/jclin path-2015-203089.

52. Lee M, Heo SH, Song IH, Rajayi H, Park HS, Park IA, et al. Presence of tertiary lymphoid structures determines the level of tumor-infiltrating lymphocytes in primary breast cancer and metastasis. Mod Pathol. 2019;32(1):70-80. https://doi.org/10.1038/s41379-018-0113-8.

53. Dieu-Nosjean MC, Antoine M, Danel C, Heudes D, Wislez M, Poulot V, et al. Long-term survival for patients with non-small-cell lung cancer with intratumoral lymphoid structures. J Clin Oncol. 2008;26(27):4410-7. https://doi.org/10.1200/JCO.2007.15.0284.

54. Seow DYB, Yeong JPS, Lim JX, Chia N, Lim JCT, Ong CCH, et al. Tertiary lymphoid structures and associated plasma cells play an important role in the biology of triple-negative breast cancers. Breast Cancer Res Treat. 2020;180(2):369-77. https:// doi.org/10.1007/s10549-020-05548-y.

Publisher's Note Springer Nature remains neutral with regard to jurisdictional claims in published maps and institutional affiliations. 